\title{
Online Web Software Package for Movement of Personnel on Duty for Official Purposes: A Step towards E-Administration
}

\author{
A Mageswari \\ Scientist ' $D$ ' \\ Combat Vehicles Research \& \\ Development Establishment
}

\author{
K Nibeesh \\ Technical Officer ' $A$ ' \\ Combat Vehicles Research \& \\ Development Establishment
}

\begin{abstract}
In any organization, it is very difficult to track the movement of an employee proceeding on duty for official purposes. Initiating manual forms and to get approvals manually will accumulate more time and is a laborious job. To automate this activity, a new online web software package for movement of personnel on duty for official purposes is designed, developed and implemented in CVRDE.
\end{abstract}

\section{Keywords}

Web Application, ASP.NET, ORACLE, C SHARP, eAdministration, duty moves, database, Index selection, Encryptions, Decryption, Information security, Central Pay Commission (CPC).

\section{INTRODUCTION}

To proceed for official duty move, employee has to initiate the application through hardcopy filled form and the application has to be taken by the employee on hand to get the respective approvals. After getting sanction for duty move from all on hardcopy, employee has to approach the task holder of the concerned Admin section for getting the movement order. Then the employee has to sign the manually calculated advance bill in Finance section. In this process, the employee has to waste time and has to undergo mental tension. Again for final settlement and claims, the employee will find it difficult to fill claims with manual calculations and in turn, it will be hectic for the task holder of Finance section to cross-check the eligibility and the manual calculations submitted by the employee.

In Admin and Finance sections, the task holders will be loaded with abundant work, like preparing the manual advance bills, maintain manual registers for advance details and settlement details of all employees proceeding on duty for official purposes [2][6].

With this background, to improve the efficiency of the system and reduce the time variant in the process of productive management, thereby to erase the mental stress undergone by the employees for simple administrative procedures and to minimize the manual interventions on calculations of advance and claims, the online application for movement of personnel on official duty was designed, developed and implemented successfully in CVRDE.

\section{SOFTWARE DESCRIPTION}

This software is for movement of personnel on duty for official purposes in which the application can be initiated online through organizational intranet with online routing to approvers for online approval, online generation of movement order for Administration department with automated duty advance calculation. On return from official duty, the employee can settle the final claims through online entry by retrieving the saved duty data in order to complete the transaction.

This software package will be helpful for the employees to initiate their official duty moves through online and will be routed to their respective approvers through Intranet. Organization Routing Structure Module is also developed as a part of this project which enables the routing for the online applications of the respective employees. Employees can initiate, modify and forward their applications online and get approval also over the Intranet. It comes as a web-enabled application with great consideration of the available flexibility. This software package is a perfect platform for reengineering the duty move processes with more efficient and detailed reports and also achieving a new level of communication through online with complete up-to-date status.

This Package assists system administration tasks and also provides an automated initiation of applications minimizing the interference of paper and manpower. The module includes User Login, Application Initiation, Application Modification, Application Forwarding/ Routing, Approver Screen, and Application Status with Reports. User Login module helps all the employees to login to the module with user rights and approvers can login with approver rights. All employees can initiate the online duty move application through application initiation either in bulk (group of employees) or individual and save the application. Initiated applications can be modified through application modification module. Routing Structure module is developed for routing the employees' application to their respective approvers as per organization structure. Approver Screen is developed for Forwarding/ Recommendations/ Sanctions/ Rejections by the approvers. Application status and reports help the individual to view the actual status of the forwarded application (whether forwarded/ sanctioned/ rejected) and respective reports through online.

Security issues and user rights are handled with utmost care and efficiency, keeping in view the organization defined security rules and regulations. All have the privilege to view the status of current moves with authorized information.

\section{SOFTWARE DEVELOPMENT}

\subsection{Software Features}

The software was designed and developed using ASP.NET, C\#.net and ORACLE 11g. The objectives of ASP.NET are to provide a consistent object-oriented environment to develop applications, to provide a code execution environment that simplifies deployment and versioning, to provide a code execution environment that guarantees the safety of the code that is executing, to provide a code execution environment that eliminates the issues faced by scripted environments with respect to performance, to provide a common programming 
model where the choice of a programming language becomes a matter of choice.

Advantages of using ASP.NET are separation of Code from HTML (makes it much easier for teams of programmers and designers to collaborate efficiently), Support for compiled languages (ASP.NET pages do not suffer the performance penalties associated with interpreted code), Graphical Development Environment, State management (ASP.NET provides solutions for session and application state management), Update files while the server is running (Components of application can be updated while the server is online and clients are connected. The Framework will use the new files as soon as they are copied to the application. Removed or old files that are still in use are kept in memory until the clients have finished), XML-Based Configuration Files (Configuration settings in ASP.NET are stored in XML files that can be easily read and edit)[15].

For better interactivity to users, Ajax with jQuery[8] [12]is used in this web application. The Ajax have the advantages [14] such as better interactivity, easier navigation and compact. Using jQuery programmer can develop fast and concise JavaScript codes to HTML document traversing, event handling, animating, widgets, and Ajax interactions. It is free, open source software Dual-licensed under the MIT license and the GNU General Public License.

\subsection{DATABASE DESIGN CONCEPTS [9]}

The software package is developed with Oracle 11g[1] as database. As online web applications require fast response, the Queries used are optimized by Query reformation, Index Recommendation and operator optimization techniques [4][7]. Since the underlying database contains large amount of data that need to be secure, the database encryption mechanism enables following security.

Encryption mechanism can restrict the user from obtaining data in an unauthorized manner. Encryption mechanism prevents from leaking information in a database when storage mediums, such as CD-ROM, disk, and magnetic tape, are lost. Encryption mechanism can verify the authentic source of a data item. The identified important column is encrypted by the explained algorithm by Tarendra G. Rahangdale at al[10].

Web applications are mainly interrupted by SQL Injection attacks. In this an attacker attempts to use malicious crafted input strings so that the dynamic SQL queries generated by the web application is different from the structure designed by the developer. This module taken care many known SQL Injection attacks [3] like bypassing Authentication, Injection with UNION, Remote execution of stored procedures and damaging with additional injected query.

\section{SOFTWARE MODULES DESIGN}

This software package handles from initiation to approval with built in routing tree along with status at each stage. The Fig 1 shows the software modules hierarchy.

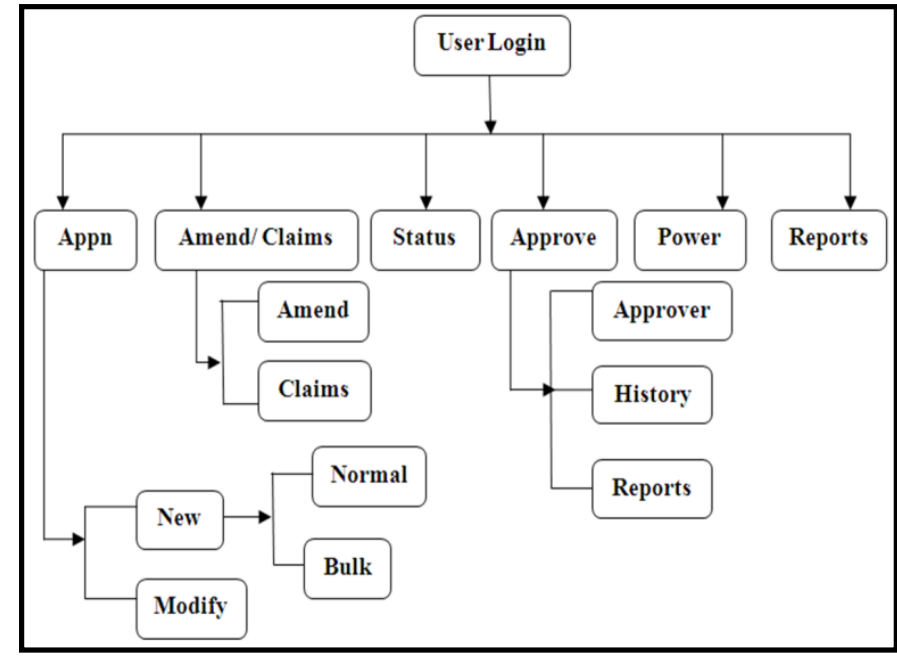

Fig 1: Software Modules

Basic requirements are handled in order to bring this module into total usage: Creating User Login, Creating Routing Structure as per Organization Chart, new application

initiation for Individual and Bulk (to initiate application in group) to capture the duty details such as basic details (Initiating Officer, Departure Date with Session, Project, Nature of Duty, Arrival Date, Justification/Reason for Move), Journey Details(Duty Place,Journey Mode, Duty Establishment/firm, Number of Days,DA at Hotel Stay) and add employee list for bulk move.

\section{ROUTING THE APPLICATIONS}

Routing the application through online is an challenging task to bring the software implementation a successful one. The initiated application will be routed to the respective approvers as per the organizational chart. In this software the normal routing will start from the employee, Section Head, Division Head, Additional Director, Budget and Director (whoever is build in the organization routing structure). In absence of approvers, the higher authority can conquest and forward the applications.

If the employee is moving for trials related activity, then it will be routed through the concerned person responsible for trials before budget clearance. Similarly if the employee is proceeding for training related activities, then the application will be routed through concerned person responsible for training before budget clearance.

Fig 2 depicts the routing followed in this software module for routing the applications. After the application is sanctioned by the sanctioning authority, it is routed to the task holder of the Administration department for generation of movement order. After generation of movement order, the application will move to the Finance task holder for generating the online advance bills. Advance calculation is being done in the software itself and the task holder can enter the fare amount for the respective journey places. As per selection of either $5^{\text {th }}$ $\mathrm{CPC}$ or $6^{\text {th }} \mathrm{CPC}$, the advance amount for the particular move will be auto calculated and advance bills are generated. 


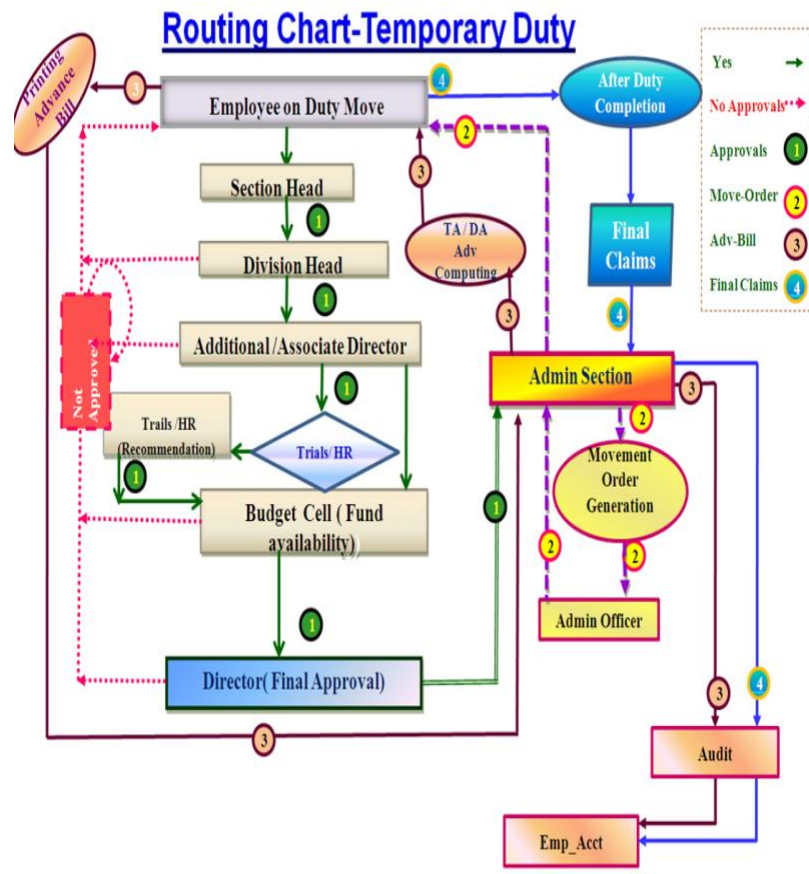

Fig 2: Routing Chart

After returning from the concerned duty, the employee has to enter the duty details and settlement report will be generated online for submission to the Finance section. The employees are provided with build in various reports for their easy reference and can view the settlement status online.

\section{SCREEN SHOTS}

Following figures are some screen shots of the application which are developed and implemented.

\section{New Application-Initiation and Forwarding}

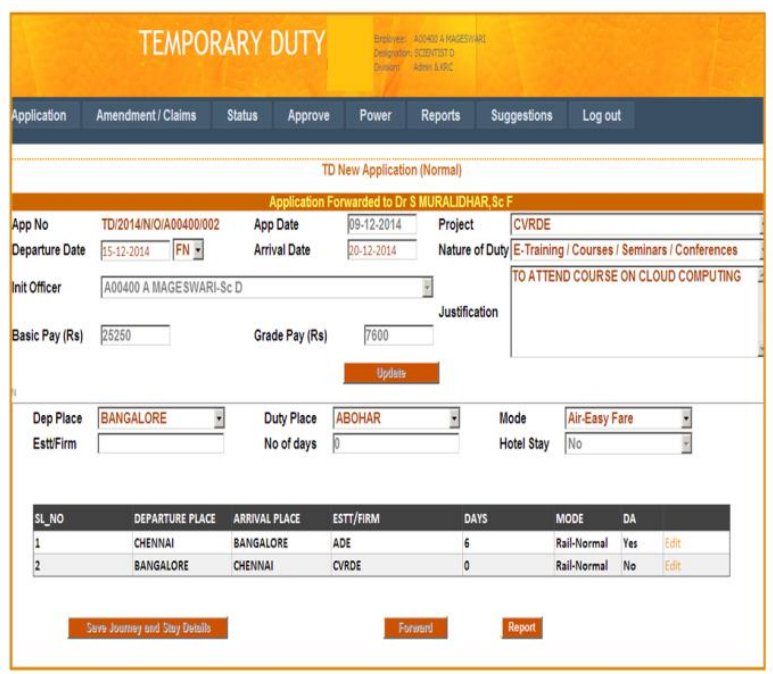

Fig 3: Initiation and Forwarding

Employees can initiate a new application using the Fig 3 screen. Journey details are entered in this screen and the application can be forwarded to next higher level approver.

Forwarded applications will reach the respective approvers and approvers can recommend / approve according to their power level as seen in Fig 4. Employees can view the current status of the application from their desk (Fig 5).

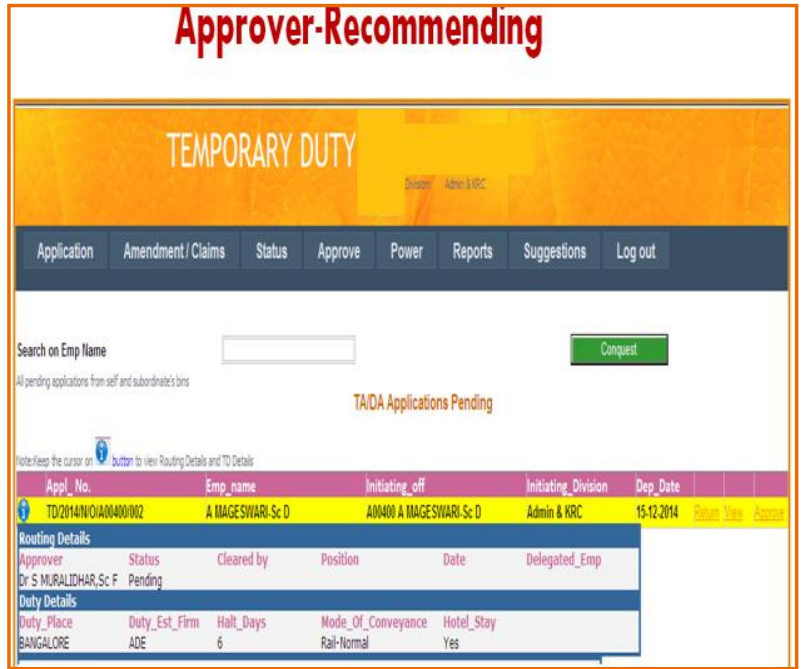

Fig 4: Approver Screen

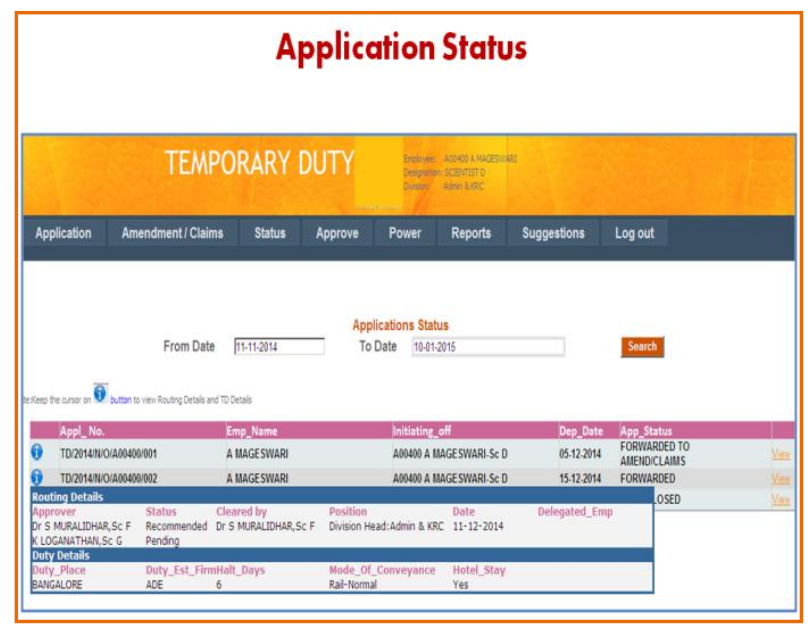

Fig 5: Application Status

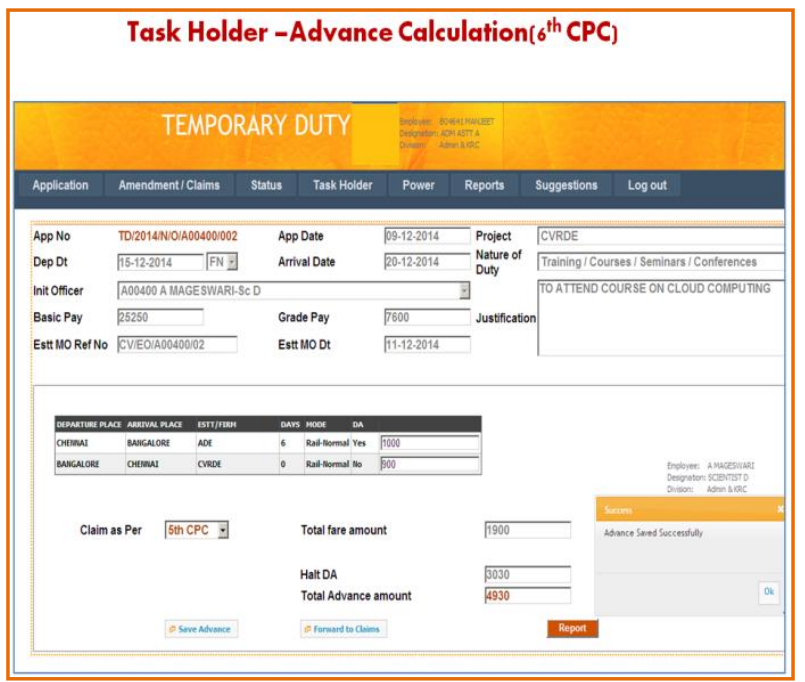

Fig 6: Advance Calculation

After movement order is generated, if there is any amendment in the move, and then the movement order amendment can be raised online with routing for approval. Similarly cancellation of movement order can also be initiated through online with routing. 


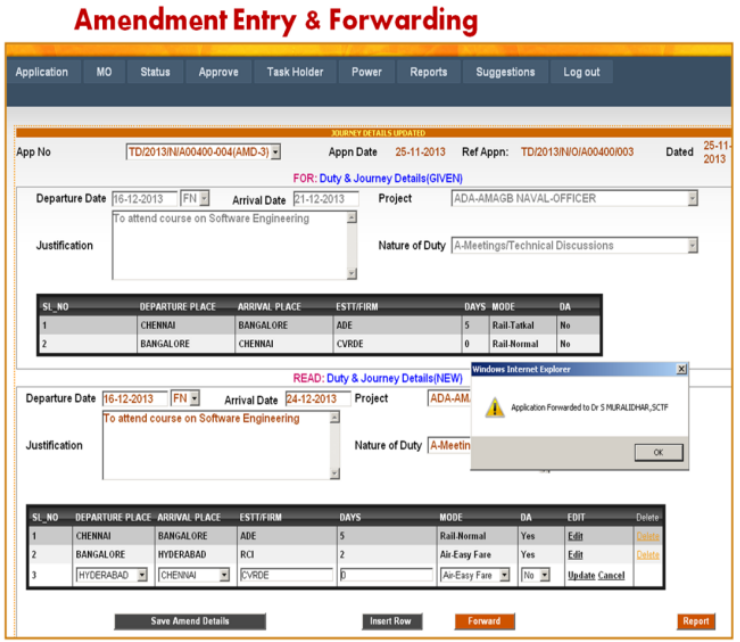

Fig 7: Amendment Entry and Forwarding

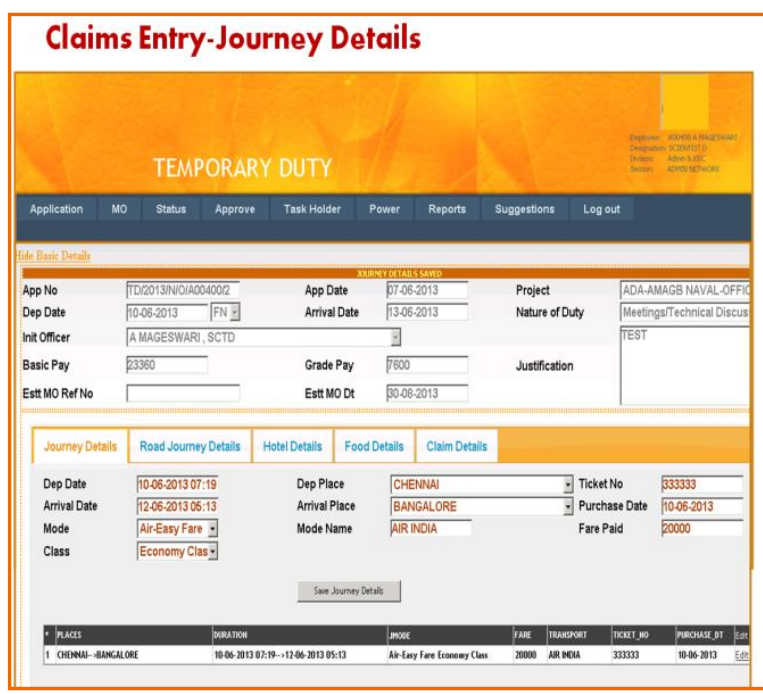

Fig 8: Claims Entry

\section{CONCLUSION AND FUTURE WORK}

Online web software for movement of personnel on duty for official purposes has been successfully implemented in CVRDE. This is achieved as a step towards e-Administration [6]. This software package is used for online initiation of application for official duty with routing and online approval.

Administration can monitor the movement of personnel proceeding on duty for official purposes for various projects. No manual intervention is involved in computing the advance and settling the claims. Advance details and settlement details are captured online and system generated registers are maintained.

Non redundant and reliable data, through single window update architecture is followed. This data bank on employees moving on duty helps in providing various management information reports for effective Administration.

In future, this software package can be linked online with Access Control Attendance Monitoring System to monitor the employees moving on official duty and regularize the attendance of employees.

\section{ACKNOWLEDGMENTS}

The authors express sincere thanks to the Director, CVRDE for providing facilities for development of the software and implementing the same.

\section{REFERENCES}

[1] Bob Bryla, "Oracle Database 11g- DBA Handbook",Tata McGraw-Hill,2008.

[2] Darmawan Napitupulu, "The Critical Success Factors Study for e-Government Implementation", International Journal of Computer Applications (IJCA) (0975 - 8887), Volume 89 - No 16, March 2014.

[3] Debasish Das, " An Approach to Detection of SQL Injection Attack Based on Dynamic Query Matching ", International Journal of Computer Applications (IJCA) (0975 - 8887), Volume 1 - No. 25, 2010.

[4] Dhaval Patel, "A Review Paper on Different Approaches for Query Optimization using Schema Object base View", International Journal of Computer Applications (IJCA) (0975 - 8887), Volume 114 - No. 4, March 2015.

[5] Mazen Kamal Qteishat, Ph.D. "The Impact of Information System Success Factors, Human Resource Staff Satisfaction, and E-Human Resource Use on Organizational Benefit", International Journal of Computer Applications (IJCA) (0975 - 8887), Volume 105 - No. 2, November 2014.

[6] Manjot Kaur, "E-Government: Challenges for Acceptance and Adoption in State of Punjab" International Journal of Computer Applications (IJCA) (0975 - 8887), Volume 109 - No. 15, January 2015.

[7] Pratham L. Bajaj, “A Survey on Query Performance Optimization by Index Recommendation"., International Journal of Computer Applications (IJCA) (0975 - 8887), Volume 113 - No. 19, March 2015.

[8] Suprotim Agarwal ,"51 Tips, Tricks and Recipes with jQuery and ASP.NET Controls.", A2Z Knowledge Visuals Pvt. Ltd.

[9] Ramez Elmasri, "Fundamentals of Database Systems", $5^{\text {th }}$ Edition, Person, 2013.

[10] Tarendra G. Rahangdale, "A Proposed Algorithm for Database Encryption and Decryption", International Journal of Computer Applications (IJCA) (0975 - 8887), National Conference on Emerging Trends in Computer Technology (NCETCT-2014).

[11] Vandana Dwivedi, "Web Application Vulnerabilities: A Survey", International Journal of Computer Applications (IJCA) (0975 - 8887), Volume 108 - No. 1, December 2014.

[12] http://api.jquery.com/

[13] http://api.jquery.com/jquery.ajax/

[14] http://en.wikipedia.org/wiki/Ajax_\%28programming\%29

[15] http://traineeinfo.mindfieldsoft.com/traineeinfo/AspNet.a spx 